\title{
ANALISIS, PERANCANGAN DAN PENERAPAN AKUNTANSI PADA UKM MEDIA COMPUTER DESA PANGGUNG PELAIHARI
}

\author{
Ines Saraswati Machfiroh \\ Dosen Program Studi Akuntansi, Politeknik Negeri Tanah Laut \\ E-mail: inessaraswati.m@gmail.com
}

\begin{abstract}
Abstrak
Usaha Kecil Menengah (UKM) juga merupakan suatu unit usaha kecil yang mampu berperan dan berfungsi sebagai katup pengaman baik dalam menyediakan alternatif kegiatan usaha produktif, alternatif penyaluran kredit, maupun dalam hal penyerapan tenaga kerja. Masalah utama dalam pengembangan UKM yaitu mengenai pengelolaan keuangan dalam usahanya tersebut. Secara umum, akuntansi dapat didefinisikan sebagai sistem informasi keuangan yang menghasilkan laporan kepada pihak-pihak yang berkepentingan mengenai aktivitas ekonomi dan kondisi perusahaan. Siklus akuntansi adalah perputaran atau urutan setiap kejadian atau proses transaksi yang kemudian dianalisa sehingga mengakibatkan terbentuknya sebuah laporan keuangan. Ada tiga tahap dalam siklus akuntansi proses pencatatan, pengikhtisaran dan pelaporan keuangan. Objek dalam penelitian ini adalah Usaha Kecil Menengah (UKM) Service Komputer yang bernama Media Computer. Data yang digunakan dalam penelitian ini adalah data primer. Metode pengumpulan data yang dilakukan dalam penelitian ini terdiri dari, yaitu: pengamatan (observasi) dan wawancara (interview). Media Computer sebelumnya tidak pernah menyusun dan membuat laporan keuangan usaha yang dijalaninya tersebut. Berdasarkan hal tersebut di atas, penulis berusaha membantu Usaha Kecil Menengah (UKM) Media Computer dalam merancang dan menyajikan laporan keuangan berdasarkan pada teori yang ada dengan menerapkan siklus akuntansi sehingga dapat dihasilkan laporan keuangan yang baik, sesuai dan memadai dengan usaha Media Computer. Hal tersebut dapat berguna bagi Usaha Kecil Menengah (UKM) media computer untuk mengetahui keadaan keuangan usahanya, membuat analisa sebelum mengambil keputusan, dan berguna dikemudian hari untuk memperoleh dana pinjaman modal dari bank untuk meningkatkan usahanya.
\end{abstract}

Kata kunci: akuntansi, siklus akuntansi, UKM service komputer

\begin{abstract}
Small and Business Medium (UKM) is also a small business unit that can play a role and function as a safety valve both in providing alternative productive business activities, alternative lending, and in terms of employment. The main problem in the development of UKM is about financial management in the business. In general, accounting can be defined as a financial information system that generates reports to interested parties regarding economic activity and company conditions. Accounting cycle is the rotation or sequence of each event or transaction process which is then analyzed so as to result in the formation of a financial report. There are three stages in the accounting cycle of the process of recording, summarizing and financial reporting. The object of this research is Small and Business Medium (UKM) Computer Service called Media Computer. The data used in this study is the primary data. Methods of data collection conducted in this study consist of, namely Observation (observation) and Interview (interview). Media Computer previously never compiled and made the financial statements of the business it lived. Based on the above, the author tries to help Small and Business Medium (UKM) Media Computer in designing and presenting financial statements based on existing theory by applying accounting cycle so that it can produce good financial report, appropriate and adequate with effort of Media Computer. It can be useful for Small and Business Medium (UKM) Media Computer to know the financial condition of its business, make an analysis before making a decision, and useful later in order to obtain capital loan funds from banks to increase business.
\end{abstract}

Keywords: accounting, accounting cycle, computer Service UKM 


\section{PENDAHULUAN}

UKM (Usaha Kecil Menengah) merupakan kegiatan ekonomi rakyat yang berskala kecil dengan bidang usaha yang secara ma-yoritas merupakan kegiatan usaha kecil dan perlu dilindungi oleh pemerintah untuk men-cegah dari persaingan usaha yang tidak sehat. Usaha Kecil Menengah (UKM) juga merupakan suatu unit usaha kecil yang mampu berperan dan berfungsi sebagai katup pengaman baik dalam menyediakan alternatif kegiatan usaha produk-tif, alternatif penyaluran kredit, maupun dalam hal penyerapan tenaga kerja. Masalah utama dalam pengembangan UKM yaitu mengenai pengelolaan keuangan dalam usahanya tersebut. Padahal dengan adanya laporan keuangan akan memungkinkan pemilik memperoleh data dan informasi khususnya keuangan yang tersusun secara sistematis dan pemilik juga dapat memperhitungkan keuntungan yang diperoleh, mengetahui berapa tambahan modal yang dicapai serta dapat mengetahui bagaimana keseimbangan hak dan kewajiban yang dimiliki. Sehingga setiap keputusan yang diambil oleh pemilik dalam mengembangkan usahanya akan didasarkan pada kondisi konkret keuangan yang dilaporkan secara lengkap bukan hanya didasarkan pada asumsi semata.

\section{METODE PENELITIAN}

\section{Objek Penelitian}

Objek dalam penelitian ini adalah Usaha Kecil Menengah (UKM) service komputer yang bernama Media Computer.

\section{Data Penelitian}

Data yang digunakan dalam penelitian ini adalah data primer, yaitu data yang diperoleh secara langsung dari usaha yang menjadi objek penelitiannya berupa hasil wawancara yang dilakukan kepada pemilik UKM tersebut se-hubungan dengan data yang diperlukan dan hasil observasi penulis pada UKM tersebut.

\section{Metode Pengumpulan Data}

Metode pengumpulan data yang dilakukan dalam penelitian ini terdiri dari, yaitu: (1) Pengamatan (observasi) dengan meninjau dan mempelajari secara langsung UKM Media Computer agar memperoleh data yang di-perlukan sehubungan masalah yang sedang diteliti. (2) Wawancara (interview) yaitu me-nanyakan langsung kepada pemilik UKM Media Computer.

\section{Metode Pengolahan Data}

Metode pengolahan data yang dilakukan dalam penelitian ini terdiri dari, yaitu: (1) Mencatat transaksi ke dalam jurnal; (2) Memindah bukukan jurnal (posting) dari jurnal ke buku besar; (3) Membuat neraca saldo; (4) Membuat Laporan Keuangan yaitu Laporan LabaRugi

\section{HASIL DAN PEMBAHASAN}

\section{Profil Objek Penelitian}

Penelitian ini dilakukan pada sebuah usaha UKM yang bergerak pada usaha jasa service computer yang bernama Media Computer. Usaha tersebut beralamat di Jalan Desa Pemuda Perumahan Griya Utama Panggung Blok C6 RT 3B Desa Panggung, Kecamatan Pelaihari, Kabupaten Tanah Laut, Provinsi Kalimantan Selatan. Pemilik usaha tersebut adalah Tuan Agus Harianto. Usaha tersebut dilakukan dirumahnya sendiri. Dari adanya kegiatan usaha ini pemilik bertujuan dapat memberikan jasa service computer. Pemilik juga dapat menyerap tenaga kerja di lingkungan masyarakat sekitar sehingga mengurangi pengangguran yang ada pada daerah tersebut dan memanfaatkan keahlian yang dimilikinya. 


\section{Analisis Objek Penelitian}

Dalam menjalankan usahanya, pemilik menangani sendiri usahanya tanpa adanya bantuan dari orang lain. Selama ini Media Computer tidak pernah membuat maupun me-nyusun laporan keuangan yang sesuai dan memadai dengan usaha yang dijalankannya. UKM Media Computer melakukan pencatatan berupa transaksi pembelian peralatan computer yang berkaitan dengan service computer dan transaksi pendapatan atas jasa service computer sehingga tidak pernah diketahui berapa besar laba atau rugi yang diperoleh dan berapa besar modal yang telah dilakukannya selama pe-nyelenggaraan kegiatan usahanya. Untuk itu penulis ingin membantu memberikan gambaran pembuatan laporan keuangan dengan menerapkan siklus akuntansi, sehingga dihasilkan laporan keuangan yang sesuai dan memadai bagi UKM Media Computer.

Dalam mengerjakannya penulis mengguna-kan bantuan program Microsoft Excel pada komputer. Langkah awal yang dilakukan sebe-lum menyusun laporan keuangan dengan me-nerapkan siklus akuntansi adalah mengumpul-kan data-data yang ada dan diperlukan, yaitu data pembelian, data pendapatan atas jasa service computer dan data transaksi yang terjadi selama kegiatan usaha berlangsung selama Juli dan Agustus 2017. Pembuatan laporan keuangan dengan menerapkan siklus akuntansi pada Media Computer dimulai dengan menjurnal setiap transaksi ke dalam jurnal umum. Selanjutnya data dari jurnal umum dipindahkan (diposting) ke dalam buku besar. Saldo setiap perkiraan di buku besar digunakan untuk menyusun neraca saldo awal. Kemudian dibuat laporan laba-rugi sehingga siap digunakan untuk penyusunan laporan keuangan untuk periode berikutnya.

\section{Data Penelitian dan Identifikasi Transaksi}

Tuan Agus Harianto mendirikan usaha jasa service computer yang diberi nama Media Computer yang didirikan pada 27 November 2007 dengan modal awal Rp50.000.000,00. Transaksi yang terjadi selama Juli dan Agustus 2017 adalah sebagai berikut:

\section{Bulan Juli 2017}

1 Juli Membeli perlengkapan sebesar Rp $50.000,00$

5 Juli Diterima pendapatan jasa atas perbaikan komputer sebesar Rp350.000,00

8 Juli Diterima pendapatan atas jasa service komputer sebesar Rp350.000,00

9 Juli Dibeli peralatan berupa battery sebesar Rp800.000,00

10 Juli Membeli peralatan secara kredit sebesar Rp500.000,00

13 Juli Diterima pendapatan atas instal kompu-ter sebesar Rp150.000,00

15 Juli Menerima pendapatan jasa service kom-puter sebesar Rp350.000,00

18 Juli Membeli peralatan Rp500.000,00

20 Juli Menerima pendapatan jasa atas perbaikan Keyboard sebesar Rp100.000,00

23 Juli Membayar tagihan listrik sebesar Rp100.000,00

25 Juli Menerima setengah pembayaran untuk perbaikan battery sebesar Rp400.000,00 dan yang belum dibayar Rp450.000,00

28 Juli Membayar biaya transportasi kirim sebesar Rp 80.000,00

30 Juli Mendapat uang atas perbaikan jasa service komputer sebesar Rp300.000,00

\section{Bulan Agustus 2017}

$\begin{array}{lll}1 \text { Agustus } & \begin{array}{l}\text { Diterima pendapatan } \\ \text { kom-puter }\end{array} & \begin{array}{l}\text { service } \\ \text { sebesar }\end{array} \\ & \text { Rp350.000,00 }\end{array}$ 
per-baikan

komputer

Rp500.000,00

6 Agustus Dibeli peralatan komputer sebesar Rp1.500.000,00

9 Agustus Dibeli perlengkapan komputer se-besar Rp50.000,00

13 Agustus Diterima pendapatan jasa service komputer sebesar Rp150.000,00

15 Agustus Diterima pendapatan jasa sebesar Rp500.000,00

17 Agustus Diterima pendapatan jasa sebesar Rp300.000,00

18 Agustus Membayar biaya transportasi kirim sebesar Rp50.000,00

19 Agustus Diterima pembayaran atas perbaikan komputer Rp350.000,00

21 Agustus Menerima pembayaran atas per-baikan komputer Rp500.000,00

23 Agustus Membayar tagihan listrik sebesar Rp100.000,00

23 Agustus Dibeli peralatan komputer berupa battery sebesar Rp1.000.000,00 se-cara kredit

25 Agustus Dibeli peralatan berupa hardisk sebesar Rp800.000,00

25 Agustus Diterima pendapatan jasa atas perbaikan

hardisk Rp850.000,00

28 Agustus Diterima pendapatan service se-besar Rp500.000,00

29 Agustus Dibayar peralatan yang dibeli secara kredit pada tanggal sebelumnya sebesar Rp1.000.000,00

30 Agustus Diterima pendapatan jasa sebesar Rp350.000,00

31 Agustus Diterima pendapatan jasa sebesar Rp300.000,00

\section{Pembuatan Akun dan Penomeran}

Penulis merancang dan menyajikan pem-buatan akun dan penomoran yang dianggap sesuai untuk UKM Media Computer ber-dasarkan pada transaksitransaksi yang terjadi selama bulan Juni, Juli dan Agustus 2017.

TABEL 1

NOMOR AKUN DAN NAMA AKUN PADA UKM MEDIA COMPUTER

\begin{tabular}{|c|l|}
\hline Nomor Akun & \multicolumn{1}{|c|}{ Nama Akun } \\
\hline 111 & Kas \\
\hline 112 & Piutang usaha \\
\hline 113 & Peralatan \\
\hline 114 & Perlengkapan \\
\hline 211 & Hutang usaha \\
\hline 411 & Pendapatan jasa \\
\hline 511 & Beban listrik \\
\hline 512 & Beban transportasi \\
\hline
\end{tabular}

Jurnal Umum

TABEL 2

MEDIA COMPUTER

JURNAL UMUM

PER 31 JULI 2017

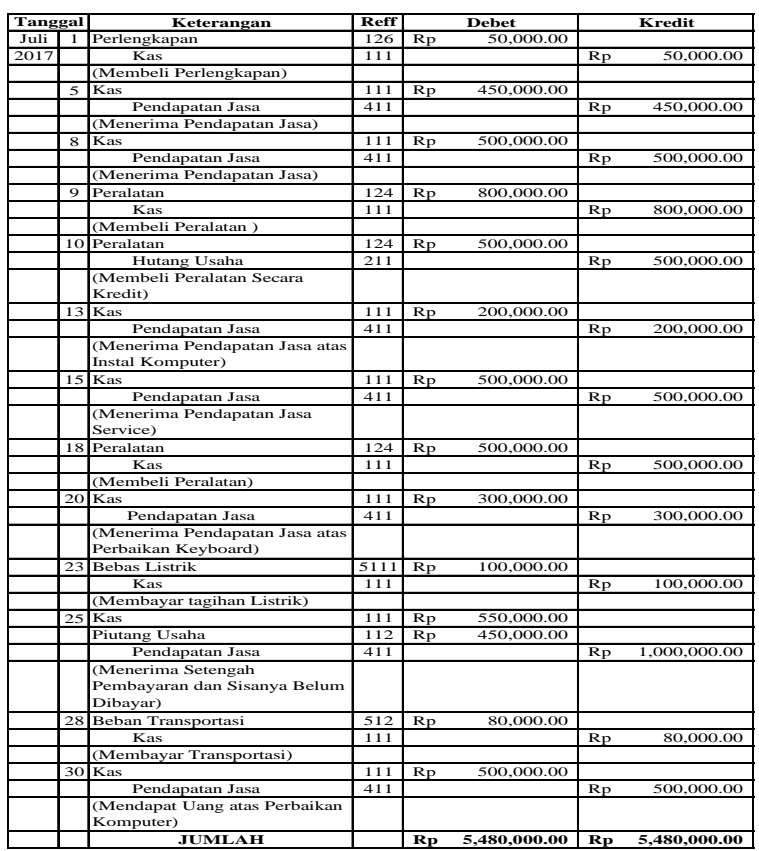


TABEL 3

MEDIA COMPUTER

JURNAL UMUM

PER 31 AGUSTUS 2017

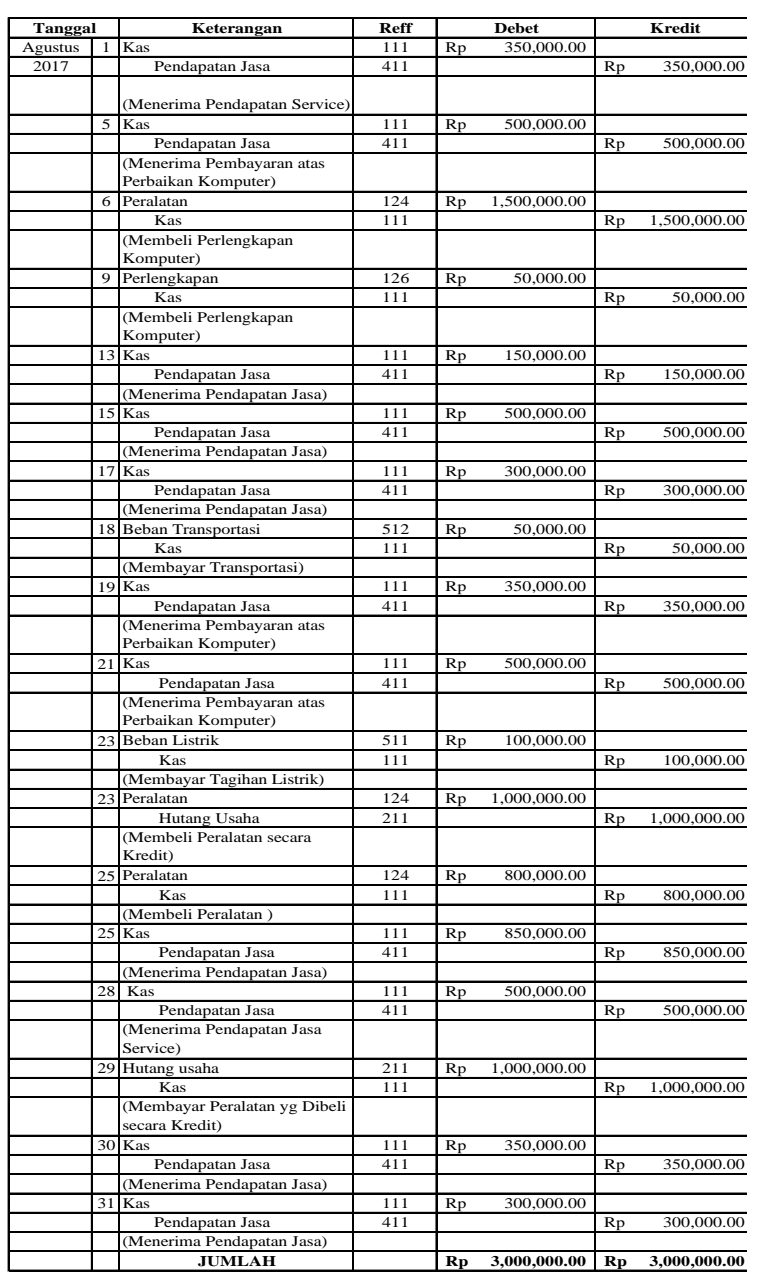

\section{Buku Besar}

TABEL 6

MEDIA COMPUTER

BUKU BESAR

PER 31 JULI 2017

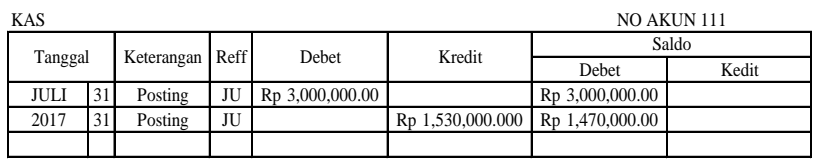

\begin{tabular}{|c|c|c|c|c|c|c|c|c|}
\hline \multicolumn{6}{|c|}{ PIUTANG USAHA } & & \multicolumn{2}{|c|}{ NO AKUN 112} \\
\hline \multirow{2}{*}{ Tanggal } & \multirow{2}{*}{ Keterangan } & \multirow{2}{*}{ Reff } & \multirow{2}{*}{\multicolumn{2}{|c|}{ Debet }} & \multirow{2}{*}{ Kredit } & \multicolumn{3}{|c|}{ Saldo } \\
\hline & & & & & & & Debet & Kedit \\
\hline \begin{tabular}{l|l} 
JULI & 3 \\
\end{tabular} & Posting & $\mathrm{JU}$ & $\mathrm{Rp}$ & $450,000.00$ & & & $450,000.00$ & \\
\hline 2017 & & & & & & & & \\
\hline
\end{tabular}

PERALATAN
\begin{tabular}{|c|c|c|c|c|c|c|c|}
\hline \multicolumn{2}{|c|}{ Tanggal } & \multirow{2}{*}{ Keterangan } & \multirow{2}{*}{ Reff } & \multirow{2}{*}{ Debet } & \multirow{2}{*}{ Kredit } & \multicolumn{2}{|c|}{ NO AKUN 124} \\
\cline { 6 - 8 } & & & Debet & Kedit \\
\hline JULI & 31 & Posting & JU & Rp $1,800,000.00$ & & Rp $1,800,000.00$ & \\
\hline 2017 & & & & & & & \\
\hline
\end{tabular}

\begin{tabular}{|c|c|c|c|c|c|c|c|c|}
\hline \multicolumn{6}{|c|}{ PERLENGKAPAN } & \multicolumn{3}{|c|}{ NO AKUN 126} \\
\hline \multirow{2}{*}{ Tanggal } & \multirow{2}{*}{ Keterangan } & \multirow{2}{*}{ Reff } & \multirow{2}{*}{\multicolumn{2}{|c|}{ Debet }} & \multirow{2}{*}{ Kredit } & \multicolumn{3}{|c|}{ Saldo } \\
\hline & & & & & & & Debet & Kedit \\
\hline \begin{tabular}{l|l} 
JULI & 31 \\
\end{tabular} & Posting & $\mathrm{JU}$ & Rp & $50,000.00$ & & & $50,000.00$ & \\
\hline 2017 & & & & & & & & \\
\hline
\end{tabular}

\begin{tabular}{|c|c|c|c|c|c|c|}
\hline \multicolumn{5}{|c|}{ HUTANG USAHA } & \multicolumn{2}{|c|}{ NO AKUN 211} \\
\hline \multirow{2}{*}{ Tanggal } & \multirow{2}{*}{ Keterangan } & \multirow{2}{*}{ Reff } & \multirow{2}{*}{ Debet } & \multirow{2}{*}{ Kredit } & \multicolumn{2}{|c|}{ Saldo } \\
\hline & & & & & Debet & Kedit \\
\hline \begin{tabular}{l|l|} 
JULI & 31 \\
\end{tabular} & Posting & \begin{tabular}{|l|}
$\mathrm{JU}$ \\
\end{tabular} & & $\begin{array}{ll}\text { Rp } & 500,000.000 \\
\end{array}$ & & $\begin{array}{ll}\mathrm{Rp} & 500,000.000 \\
\end{array}$ \\
\hline 2017 & & & & & & \\
\hline
\end{tabular}

PENDAPATAN JASA

\begin{tabular}{|c|c|c|c|c|c|c|}
\hline \multirow[b]{2}{*}{ Tanggal } & \multirow[b]{2}{*}{ Keterangan } & \multirow[b]{2}{*}{ Reff } & \multirow[b]{2}{*}{ Debet } & \multirow[b]{2}{*}{ Kredit } & \multicolumn{2}{|c|}{ Saldo } \\
\hline & & & & & Debet & Kedit \\
\hline \begin{tabular}{l|l} 
JULI \\
\end{tabular} & Posting & $\mathrm{JU}$ & & Rp 3,450,000.000 & & Rp 3,450,000.000 \\
\hline 2017 & & & & & & \\
\hline
\end{tabular}

\begin{tabular}{|c|c|c|c|c|c|c|c|c|}
\hline \multicolumn{6}{|c|}{ BEBAN LISTRIK } & \multirow{2}{*}{\multicolumn{3}{|c|}{$\begin{array}{c}\text { NO AKUN } 511 \\
\text { Saldo }\end{array}$}} \\
\hline \multirow{2}{*}{ Tanggal } & \multirow{2}{*}{ Keterangan } & \multirow{2}{*}{ Reff } & \multirow{2}{*}{\multicolumn{2}{|c|}{ Debet }} & \multirow{2}{*}{ Kredit } & & & \\
\hline & & & & & & \multicolumn{3}{|c|}{ Debet } \\
\hline \begin{tabular}{l|l} 
JULI & 31 \\
\end{tabular} & Posting & $\mathrm{JU}$ & $\mathrm{Rp}$ & $\begin{array}{l}100,000.00 \\
\end{array}$ & & & $\begin{array}{l}100,000.00 \\
\end{array}$ & \\
\hline 2017 & & & & & & & & \\
\hline
\end{tabular}

BEBAN TRANSPORTASI

NO AKUN 512

\begin{tabular}{|c|c|c|c|c|c|c|c|c|}
\hline \multicolumn{6}{|c|}{ BEBAN TRANSPORTASI } & \multirow{2}{*}{\multicolumn{3}{|c|}{ NO AKUN 512}} \\
\hline \multirow{2}{*}{ Tanggal } & \multirow{2}{*}{ Keterangan } & \multirow{2}{*}{ Reff } & \multirow{2}{*}{\multicolumn{2}{|c|}{ Debet }} & \multirow{3}{*}{ Kredit } & & & Saldo \\
\hline & & & & & & & Debet & Kedit \\
\hline JULI & Posting & $\mathrm{JU}$ & & $80,000.00$ & & & $80,000.00$ & \\
\hline 2017 & & & & & & & & \\
\hline
\end{tabular}

\section{Rekapitulasi}

TABEL 4

MEDIA COMPUTER

REKAPITULASI

PER 31 JULI 2017

\begin{tabular}{|c|c|c|c|c|c|c|c|}
\hline \multicolumn{4}{|c|}{ Debet } & \multicolumn{4}{|c|}{ Kredit } \\
\hline No Akun & Akun & & Total & No Akun & Akun & & $T$ \\
\hline 111 & Kas & $\mathrm{Rp}$ & $3,000,000.00$ & 111 & Kas & $\begin{array}{ll}\mathrm{Rp} & 1 \\
\end{array}$ & $\overline{1,5}$ \\
\hline 112 & Piutang Usaha & $\mathrm{Rp}$ & $450,000.00$ & 211 & Hutang Usaha & & 5 \\
\hline 124 & Peralatan & $\mathrm{Rp}$ & $1,800,000.00$ & 411 & Pendapatan Jasa & Rp 3 & $\overline{3,4}$ \\
\hline 126 & Perlengkapan & $\mathrm{Rp}$ & $50,000.00$ & & & & \\
\hline 511 & \begin{tabular}{|l|} 
Beban Listrik \\
\end{tabular} & $\mathrm{Rp}$ & $100,000.00$ & & & & \\
\hline 512 & Beban Transportasi & $\mathrm{Rp}$ & $80,000.00$ & & & & \\
\hline & JUMLAH & & $5,480,000.00$ & & JUMLAH & \begin{tabular}{|l|}
$\mathrm{Rp} 5$ \\
\end{tabular} & 5,4 \\
\hline
\end{tabular}

TABEL 5

MEDIA COMPUTER

REKAPITULASI

PER 31 AGUSTUS 2017

\begin{tabular}{|c|c|c|c|c|c|c|c|}
\hline \multicolumn{4}{|c|}{ Debet } & \multicolumn{4}{|c|}{ Kredit } \\
\hline No Akun & Akun & & Total & No Akun & Akun & & Tote \\
\hline 111 & Kas & $\overline{\mathrm{R}_{\mathrm{P}}}$ & $4,650,000.00$ & 111 & Kas & Rp & 3,50 \\
\hline 124 & Peralatan & & $3,300,000.00$ & 211 & Hutang Usaha & $\mathrm{Rp}$ & 1,00 \\
\hline 126 & Perlengkapan & $\overline{\mathrm{R}_{\mathrm{I}}}$ & $50,000.00$ & 411 & Pendapatan Jasa & $\mathrm{Rp}$ & 4,65 \\
\hline 211 & Hutang Usaha & & $1,000,000.00$ & & & & \\
\hline 511 & Beban Listrik & $\frac{\mathrm{R}_{\mathrm{l}}}{\mathrm{R}}$ & $100,000.00$ & & & & \\
\hline 512 & \begin{tabular}{|l} 
Beban Transportasi \\
\end{tabular} & & $50,000.00$ & & & & \\
\hline & MLA & & $9,150,000,00$ & & JUMLAH & & 9,15 \\
\hline
\end{tabular}


TABEL 7

MEDIA COMPUTER

BUKU BESAR

PER 31 AGUSTUS 2017

\begin{tabular}{|c|c|c|c|c|c|c|}
\hline \multicolumn{7}{|c|}{ NO AKUN 111} \\
\hline \multirow{2}{*}{ Tanggal } & \multirow{2}{*}{ Keterangan } & \multirow{2}{*}{ Reff } & \multirow{2}{*}{ Debet } & \multirow{2}{*}{ Kredit } & \multicolumn{2}{|c|}{ Saldo } \\
\hline & & & & & Debet & Kedit \\
\hline $\begin{array}{ll}\text { Agustus } & 31 \\
\end{array}$ & Posting & $\mathrm{JU}$ & Rp 4,650,000.00 & & Rp 4,650,000.00 & \\
\hline 2017 & Posting & $\mathrm{JU}$ & & Rp 3,500,000.00 & Rp 1,150,000.00 & \\
\hline \multicolumn{5}{|c|}{ PERALATAN } & \multicolumn{2}{|c|}{ NO AKUN 124} \\
\hline \multirow{2}{*}{ Tanggal } & \multirow{2}{*}{ Keterangan } & \multirow{2}{*}{ Reff } & \multirow{2}{*}{ Debet } & \multirow{2}{*}{ Kredit } & \multicolumn{2}{|c|}{ Saldo } \\
\hline & & & & & Debet & Kedit \\
\hline $\begin{array}{l}\text { Agustus } \\
\end{array}$ & Posting & $\mathrm{JU}$ & Rp 3,300,000.00 & & Rp 3,300,000.00 & \\
\hline \multicolumn{7}{|l|}{\begin{tabular}{|l|l}
2017 & \\
\end{tabular}} \\
\hline \multicolumn{5}{|c|}{ PERLENGKAPAN } & \multicolumn{2}{|c|}{ NO AKUN 126} \\
\hline \multirow{2}{*}{ Tanggal } & \multirow{2}{*}{ Keterangan } & \multirow{2}{*}{ Reff } & \multirow{2}{*}{ Debet } & \multirow{2}{*}{ Kredit } & \multicolumn{2}{|c|}{ Saldo } \\
\hline & & & & & Debet & Kedit \\
\hline $\begin{array}{l}\text { Agustus } \\
31 \\
\end{array}$ & Posting & $\mathrm{JU}$ & 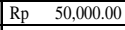 & & 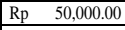 & \\
\hline 2017 & & & & & & \\
\hline \multicolumn{5}{|c|}{ HUTANG USAHA } & \multicolumn{2}{|c|}{ NO AKUN 211} \\
\hline \multirow{2}{*}{ Tanggal } & \multirow{2}{*}{ Keterangan } & \multirow{2}{*}{ Reff } & \multirow{3}{*}{ Debet } & \multirow{2}{*}{ Kredit } & & \\
\hline & & & & & Debet & Kedit \\
\hline $\begin{array}{l}\text { Agustus } \\
\end{array}$ & Posting & $\mathrm{JU}$ & & Rp 1,000,000.00 & & Rp 1,000,000.00 \\
\hline \begin{tabular}{l|l}
2017 & 31 \\
\end{tabular} & Posting & $\begin{array}{ll}\mathrm{JU} \\
\end{array}$ & Rp 1,000,000.00 & & & $\mathrm{Rp}$ \\
\hline PENDAPATF & N USAHA & & & & NO AK & UN 411 \\
\hline & & & & & & \\
\hline langgal & Keterangan & Reff & Debet & Kredit & Debet & Kedit \\
\hline $\begin{array}{ll}\text { Agustus } & 31 \\
\end{array}$ & Posting & $\mathrm{JU}$ & & Rp 4,650,000.00 & & Rp 4,650,000.00 \\
\hline 2017 & & & & & & \\
\hline BEBAN TRA & NSPORTASI & & & & $\mathrm{NO} \mathrm{AK}$ & UN 512 \\
\hline Tanggal & Keterangan & & Debet & Kredit & & \\
\hline 1 auggat & Netrongant & | & Devet & Nicult & Debet & Kedit \\
\hline $\begin{array}{l}\text { Agustus } \\
\end{array}$ & Posting & $\mathrm{JU}$ & \begin{tabular}{|ll} 
Rp & $50,000.00$ \\
\end{tabular} & & $\begin{array}{ll}\operatorname{Rp} & 50,000.00 \\
\end{array}$ & \\
\hline 2017 & & & & & & \\
\hline
\end{tabular}

\section{Neraca Saldo}

TABEL 8

MEDIA COMPUTER
NERACA SALDO
PER 31 JULI 2017

\begin{tabular}{|c|c|c|c|c|c|}
\hline NO AKUN & AKUN & & DEBET & & KREDIT \\
\hline 111 & Kas & $\mathrm{Rp}$ & $1,470,000.00$ & & \\
\hline 112 & Piutang Usaha & $\mathrm{Rp}$ & $450,000.00$ & & \\
\hline 124 & Peralatan & $\mathrm{Rp}$ & $1,800,000.00$ & & \\
\hline 126 & Perlengkapan & $\mathrm{Rp}$ & $50,000.00$ & & \\
\hline 211 & Hutang Usaha & & & $\mathrm{Rp}$ & $\overline{500,000.00}$ \\
\hline 411 & Pendapatan Jasa & & & $\mathrm{Rp}$ & $3,450,000.00$ \\
\hline 511 & Beban Listrik & $\mathrm{Rp}$ & $100,000.00$ & & \\
\hline 512 & Beban Transportasi & $\mathrm{Rp}$ & $80,000.00$ & & \\
\hline & JUMLAH & Rp & $3,950,000.00$ & $\mathrm{Rp}$ & $\begin{array}{l}3,950,000,00 \\
\end{array}$ \\
\hline
\end{tabular}

TABEL 9

MEDIA COMPUTER

NERACA SALDO

PER 31 AGUSTUS 2017

\begin{tabular}{|c|c|c|c|c|}
\hline NO AKUN & AKUN & & DEBET & KREDIT \\
\hline 111 & Kas & $\mathrm{Rp}$ & $1,150,000.00$ & \\
\hline 124 & Peralatan & $\mathrm{Rp}$ & $3,300,000.00$ & \\
\hline 126 & Perlengkapan & $\mathrm{Rp}$ & $50,000.00$ & \\
\hline 211 & Hutang Usaha & & & $\mathrm{Rp}$ \\
\hline 411 & Pendapatan Usaha & & & $\begin{array}{ll}\mathrm{Rp} & 4,650,000.00 \\
\end{array}$ \\
\hline 511 & Beban Listrik & $\mathrm{Rp}$ & $100,000.00$ & \\
\hline 512 & Beban Transportasi & $\mathrm{Rp}$ & $50,000.00$ & \\
\hline & JUMLAH & $\mathbf{R p}$ & $4,650,000.00$ & $\begin{array}{ll}\text { Rp } & 4,650,000.00 \\
\end{array}$ \\
\hline
\end{tabular}

\section{Laporan Keuangan Laba-Rugi}

$$
\begin{aligned}
& \text { Media Computer } \\
& \text { Laporan Laba-Rugi } \\
& \text { Per } 31 \text { Juli } 2017
\end{aligned}
$$

\section{PENDAPATAN}

Pendapatan Usaha/Jasa Rp 3.450.000,00

\section{Jumlah Pendapatan Usaha/Jasa Rp}

\subsubsection{0,00}

\section{BEBAN}

Beban Listrik Rp 100.000,00

Beban Transportasi $\quad \mathrm{Rp}$ $80.000,00$

$$
\begin{gathered}
\text { Media Computer } \\
\text { Laporan Laba-Rugi } \\
\text { Per } 31 \text { Agustus } 2017
\end{gathered}
$$

\section{PENDAPATAN}

Pendapatan Usaha/Jasa Rp 4.650.000,00

Jumlah Pendapatan Usaha/Jasa Rp 4.650.000,00

\section{BEBAN}

Beban Listrik

$$
\mathrm{Rp}
$$

100.000,00

Beban Transportasi $\quad \mathrm{Rp}$

$50.000,00$

\section{Jumlah Beban \\ 150.000,00 \\ Laba Bersih}

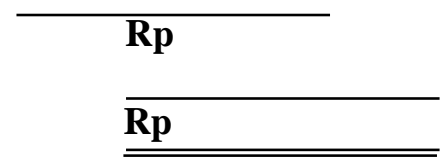

$4.500 .000,00$ 


\section{KESIMPULAN}

Media Computer sebelumnya tidak pernah menyusun dan membuat laporan keuangan usaha yang dijalaninya tersebut. Berdasarkan hal tersebut di atas, penulis berusaha membantu Usaha Kecil Menengah (UKM) Media Computer dalam merancang dan menyajikan laporan keuangan berdasarkan pada teori yang ada dengan menerapkan siklus akuntansi sehingga dapat dihasilkan laporan keuangan yang baik, sesuai dan memadai dengan usaha Media Computer. Dengan membuat laporan keuangan seperti laporan laba-rugi maka dapat berguna bagi Usaha Kecil Menengah (UKM) Media Computer untuk mengetahui keadaan keuangan usahanya, membuat analisa sebelum mengambil keputusan, dan berguna dikemudian hari untuk memperoleh dana pinjaman modal dari bank untuk meningkatkan usahanya. Dari laporan laba-rugi yang dibuat pada periode 31 Juli 2017 dan 31 Agustus 2017 dapat diketahui bahwa Usaha Kecil Menengah (UKM) Media Computer mendapatkan Laba yaitu masing-masing sebesar $\mathrm{Rp}$ 3.270.000,00 untuk periode 31 Juli 2017 dan sebesar Rp 4.500.000,00 untuk periode 31 Agustus 2017.

\section{DAFTAR PUSTAKA}

Muawanah, Umi dkk. 2008. Konsep Dasar Akuntansi dan Pelaporan Keuangan. Jilid 1. Jakarta :Direktorat Pembinaan Sekolah Menengah Kejuruan, Direktorat Jenderal Manajemen Pendidikan Dasar dan Menengah, Departemen Pendidikan Nasional 